\title{
Synthesis and Characterization of Carboxymethyl Chitosan and its Effect on Turbidity Removal of River Water
}

\author{
Zeenat M. Ali ${ }^{1 *}$, Abdul Jabbar Laghari ${ }^{2}$,Abdul Khalique Ansari ${ }^{1}$, \\ Mohammad Yar Khuhawar ${ }^{2}$ \\ ${ }^{I}$ Mehran University of Engineering \& Technology, Jamshoro, Sindh, Pakistan \\ ${ }^{2}$ Institute of Advanced Research Studies in Chemical Sciences, University of Sindh, Jamshoro, Pakistan
}

\begin{abstract}
The Chitosan derivative named Carboxymethyl Chitosan was synthesized by direct Alkylation method. The Chitosan was obtained by Chemical method from White Prawn/Indian Prawn (FenneropenaeusIndicus) and was used for preparation of Carboxymethyl Chitosan. The Chitosan composition was found $51.17 \%$ Carbon, $41.61 \%$ Oxygen and $5.22 \%$ Nitrogen with $81.3 \%$ degree of deacetylation. The prepared Carboxymethyl Chitosan was characterized by SEM, FT-IR and TGA. The Carboxymethyl Chitosan examined as flocculant for turbidity removal of Indusriver water samples. The experimental condition was optimized and found that the maximum separation efficiency was achievedat $\mathrm{pH}-7$ and $0.2 \mathrm{mg} / \mathrm{L}$ dose. The separation efficiency range placed between $81.2 \%$ and $87.1 \%$. The total suspended solids and turbidity relation was also evaluated.
\end{abstract}

Keywords -Carboxymethyl, Characterization, Chitosan, Prawn, River Indus

\section{INTRODUCTION}

The Carboxymethyl Chitosan is an amphiprotic ether derivative. It is derived from Chitosan. The Chitosan was isolated from Chitin. The Chitosan have much industrial applications. It is used in pharmaceutical industry, biomedical and water treatment etc. The Chitosan is composed of amino group and hydroxide group at primary and secondary positions which took part in reaction. The amino group is weak base, it protonated at $\mathrm{pH}$ less than 6.5 of suspension. In alkaline medium it was insoluble and forms precipitous. The internal structure of Chitosan, its Hydrogen bonding, cationic nature and degree of deacetylation influence its solubility of in aqueous solutions. Due to limited solubility, its application did goes in narrow spectrum especially in pharmaceutical industry where solubility is prime factor.

The chitosan properties were altered by chemical modification by means of grafting onto chitosan chain and make macro molecular chain. Also done by substitution of hydrophilic group in place of amino or hydroxyl group of Chitosan. The modification improves and enhances the physiochemical proprieties of Chitosan. The degree of acetylating, reactivity, solubility and molecular weight were altered. The Chitosan derivatives are the modified and altered form of Chitosan with improved physiochemical proprieties. The hydrophilic group which took part in modification and alteration were hydroxyl propyl, hydroxyalkylamine, hydroxyethyl, and Sulfate phosphate and carboxyalkyl group. The carboxyalkyl group included carboxybutyl, carboxyethyl and carboxymethyl [6]. Among all Chitosan derivatives the carboxymethyl group placed dominant position in consumption and usage. It happened because of ease of synthesis, solubility, reactivity, biodegradability, biocompatibility and non-toxicity [6]. The Carboxymethyl Chitosan were found OCarboxymethyl Chitosan, N-Carboxymethyl Chitosan and N,O-Carboxymethyl Chitosan.

There are two methods followed up for the substitution.These are Reductive alkylation method and direct alkylation method. In Reductive alkylation method the Chitosan reacted with aldehyde - Glyoxylic acid. The $\mathrm{N}_{\mathrm{a}} \mathrm{BH}_{4}$ and $\mathrm{N}_{\mathrm{a}} \mathrm{CNBH}_{3}$ used for hydrogenation. In this method the O-Substitution were not happened because of its absence while the amino group were took part in reaction.Hence Carboxymethylationis done on N-atom. The presence of glucoamine unit in Chitosan chain responsible for monoCarboxymethylation and diCarboxymethylation. The other factors were the regent concentration and reaction conditions. By the varying the conditions number of Carboxymethyl Chitosan species were formed differentiated by molecular weight distribution, molecular sizes and degree of deacetylation.

The second method was the direct alkylation. In this method the Chitosan reacted with monochloroacetic acid. The isopropanol in water were used as solvent. In this method the O-Carboxymethyl and $\mathrm{N}-\mathrm{O}$ Carboxymethyl were formed by varying the $\mathrm{pH}$. At mild $\mathrm{pH} 8$ to 8.5 , the amino group active took part in reaction and formed N-Carboxymethyl. When Sodium Hydroxide concentration increase $>20 \%$ and $\mathrm{pH}$

*Corresponding Author E-mail: hussainsaleem@uok.edu.pk 
increases the hydroxyl group became active hence substitution of Hydroxyl group done on C6 and C3 while some amino group substitution done on $\mathrm{C} 2$. The degree of deacetylation puts no impact on degree of substitution however the sodium Hydroxide concentration affects the chemistry of Carboxymethyl Chitosan [3].The Carboxymethyl Chitosan exists in dirty white to pure white powder form. The properties strictly influenced by experimental conditions of temperature and reactants' concentrations. The presence of Carboxy group in Carboxymethyl Chitosan chain enables its solubility in neural, acidic and basic medium. It is highly soluble polymer. Another property of Carboxymethyl Chitosan was its moisture adsorption and retention. This was very prominent characteristic which make its importance high in cosmetic industry and drug formation. The large hydrodynamic volume of Carboxymethyl Chitosan feasible in film formation and hydrogels making. The Carboxymethyl Chitosan was antioxidant and antimicrobial agent specially used in wood healing drugs and cell cultures agricultural and food industry for preservation and storage of fruits and vegetables from fungus and bacterias. The Carboxymethyl Chitosan was most suitable organic polymer for metal adsorption and metal Chelation. The flexible structural chemistry and hydrophilicity make feasible for metal complexation. The amino group and hydroxyl group were the active legends for metal Chelation. The hydroxyl group easily protonated in acidic solution creates the electrostatic force which attracts the anionic part of metal complexes while amino group provided the active sites for metal Chelations [6].

\section{Method For Preparation Of CARboxymethyl Chitosan}

Carboxymethyl Chitosan was prepared from Chitosan by acid-base treatment method [1],[2],[4],[5],[7]. As Chitosan exists in exo-skeleton of crustaceans, hence IndianPrawn or White Shrimp of Arabian Sea was selected for extraction of Chitosan. The White Prawn or Indian Prawn are from class of Crustacean, belongs to Penaeidae family and its Phylum is Arthropoda. The biological name of White Prawn/Indian Prawnis FenneropenaeusIndicus. Prior to preparation of Carboxymethyl Chitosan, it was analyzed and found that degree of deacetylation of Chitosan was $81.3 \%$. According to the EDX report the prepared Chitosan composed of $51.17 \%$ Carbon while the Oxygencontent was $41.61 \%$ andNitrogen content was $5.22 \%$.

The $3 \mathrm{gm}$ of extracted Chitosan was taken in conical flask than $65 \mathrm{~mL}$ isopropanol were added. It was stirring well up to $30 \mathrm{~min}$ till uniform suspension was obtained. The $40 \mathrm{gm}$ sodium Hydroxide was dissolved in double distilled water and makes $40 \%$ solution. This solution was added in conical flask the reaction was started at room temperature. The room temperature was noted $50^{\circ} \mathrm{C}$ in those days. The monochloroacetic acid solution were also prepared and added in flask. The 14.4 grams monochloroacetic acid was dissolved in $100 \mathrm{~mL}$ isopropanol. The Monochloroaceticacid solution was pouring in conical flask. The reaction followed up. The suspension was kept five hours at room temperature for complete the reaction. After five hours the suspension were filtered in glass filtered. The filtrate was recovered and washed with $100 \mathrm{~mL}$ methanol. Than it was filtered and methanol was discarded. The filtrate was neutralized by glacial acetic acid and finally ethanol was added to make it in organic phase. Finally it was filtered and dried at room temperature. The dirty white type Carboxymethyl Chitosan were obtained in lumps form. It was bump with glass rod to make small size and passes through the $100 \mathrm{~m} \mu$ screen.

\section{CHARACTERIZATION}

The synthesized Carboxymethyl Chitosan was characterized by FT-IR and TGA (Thermal Gravimetric Analysis). The SEM (Scan Electron Microscopy) was also done. The details of all are discussedin the following sections.

\subsection{Scan Electron Microscopy of Carboxymethyl Chitosan}

The Morphology of Carboxymethyl Chitosan was observed by Scan Electron Microscope (SEM) in Scanning Electron Microscope Laboratory, Centre of Pure and Applied Geology University of Sindh Jamshoro using Electron Microscope Model (JEOL 6490 LV - SEM by JAPAN). The prepared CarboxymethylChitosan from Chitosan extracted from Indian white Prawn (FenneropenaeusIndicus) was subjected for scan electron microscopy having $200 \mu \mathrm{m}$ particle size as shown in Figure-1. The scan prints showed that prepared CM-Chitosan having Crystalline, Angular and Nodular Crystals. The prints were obtained by zooming the sample 8000 times under $12 \mathrm{~kW}$ power. 


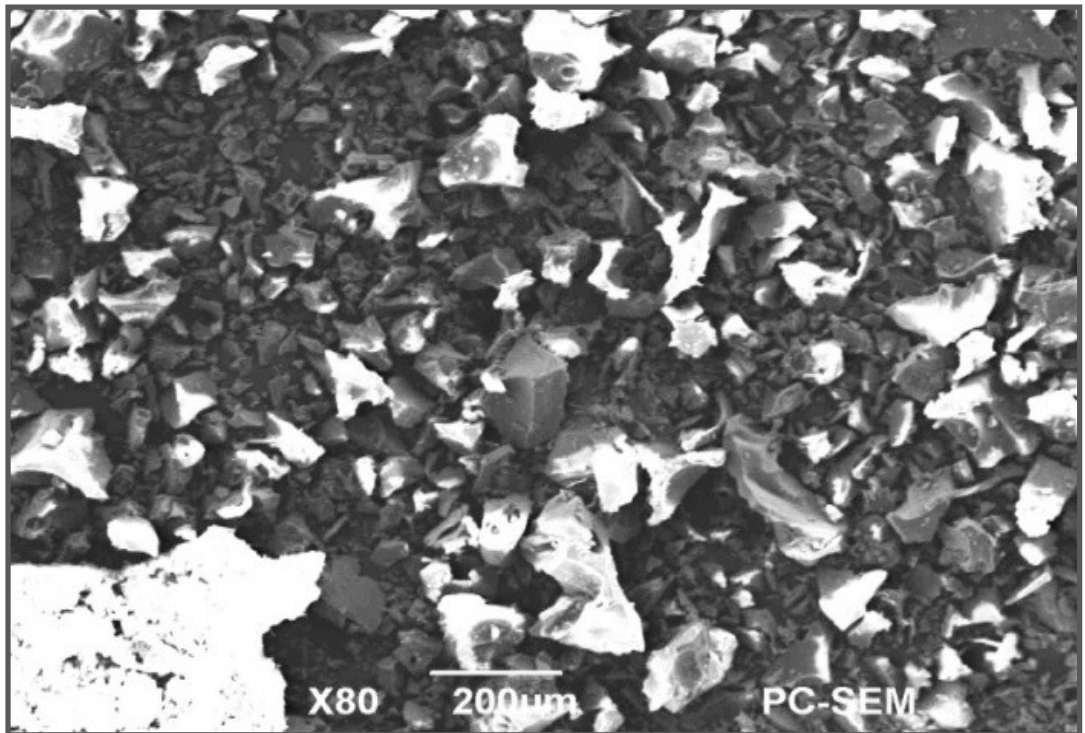

Fig.-1: The Scanning Electron Micrographs of Carboxymethyl Chitosan prepared from Chitosan extracted from White Prawn (FenneropenaeusIndicus)

\subsection{Energy Dispersive X-Ray Spectroscopy Carboxymethyl Chitosan}

Energy Dispersive X-Ray Spectroscopy (EDX or EDS) of Carboxymethyl Chitosan was done in PCSIRLab Karachivide model no JSX-3400RII Energy-Dispersive X-ray Fluorescence Spectrometer as shown in Figure-2.According to spectrum results, the content of Carbon was $55.65 \%$, Oxygen $34.36 \%$, and Nitrogen $5.30 \%$, Sodium $1.63 \%$ and Chlorine $1.91 \%$.The compositions were determined via emission of electron from K-shell.

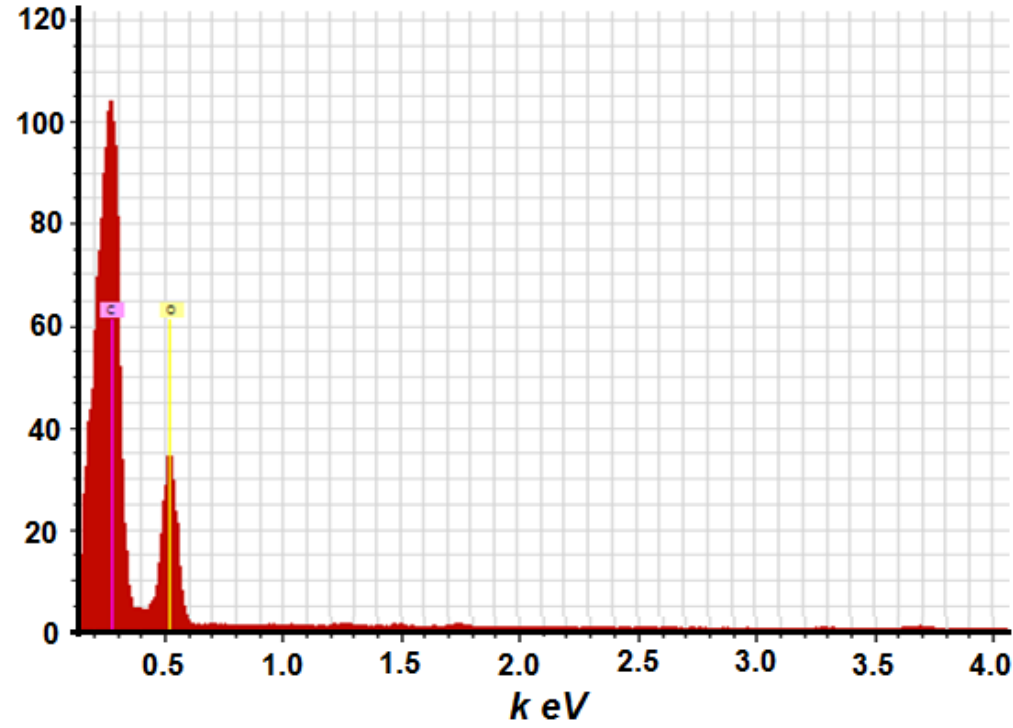

Fig.-2: EDX Spectrum of Prepared Carboxymethyl Chitosan. The profiles of Carbon, Nitrogen, Oxygen, Sodium and Chlorine are distributed on the surface of each Carboxymethyl Chitosan Skeleton.

\subsection{Fourier Transform Spectroscopy of Carboxymethyl Chitosan}

Fourier Transform Spectroscopy of Carboxymethyl Chitosan was conducted in M. A.KaziInstitute of Chemistry, University of Sindh, Jamshorovide equipment Nicolet AVATAR 330 FT-IR with an Attenuated Total Reflectance (ATR) accessory, smart performer (Thermo Nicolet, Thermo Electron Corporation USA) with $\mathrm{Zn}$-Se probe. According to FT-IR Spectraas shown in Figure-3, the bend stretched at $3436 \mathrm{~cm}^{-1}$ attributed for $\mathrm{O}-\mathrm{H}$ and N-H group. The $2900 \mathrm{~cm}^{-1}$ stretching bend express the $\mathrm{C}-\mathrm{H}$ group. The asymmetrical stretched attributed at $1634 \mathrm{~cm}^{-1}$ for $\mathrm{C}=\mathrm{O}$. At $1420 \mathrm{~cm}^{-1}$ bend stretched for the- $\mathrm{CH}_{2}-$ and $-\mathrm{CH}_{3}$ - group. The $\mathrm{C}-\mathrm{O}$ bend stretched at $1053 \mathrm{~cm}^{-1}$ and $1327 \mathrm{~cm}^{-1}$. 


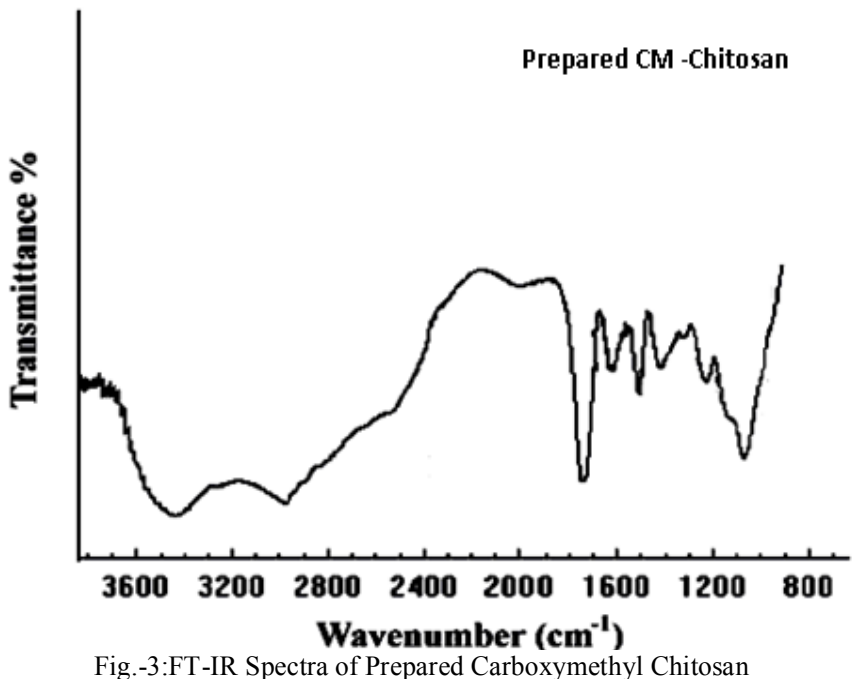

\subsection{Thermal Gravimetric Analysis (TGA) of Carboxymethyl Chitosan}

The Thermal Gravimetric Analyses describes the thermal degradation of samples. The TGA of Carboxymethyl Chitosan was conducted in PCSIR Lab Karachi vide Equipment NetzschTC 209ÎL Libra Thermal Analyzer. According to TGA Curve the thermal degradation of Carboxymethyl Chitosan was took place in three places as shown in Figure-4. The curve showed that in between $35^{\circ} \mathrm{C}-240^{\circ} \mathrm{C}$, the degradation started and weight losses occurred. The reason of weight lost were moisture content and decomposition of the cyclized product containing COC. The curve showed the removal of $\mathrm{COO}$ from polysaccharide and it was possible that at this stage carbon dioxide released from samples. As CM-Chitosan content - $\mathrm{COOH}$ group in its chain structure hence it was decarboxylated near $300^{\circ} \mathrm{C}$. The third degradation was reported and that was possible that $\mathrm{NH}_{2}$ group detached in the form of ammonia $\left(\mathrm{NH}_{3}\right)$ released. The degradation of Carboxymethyl Chitosan were done in nitrogen atmosphere.

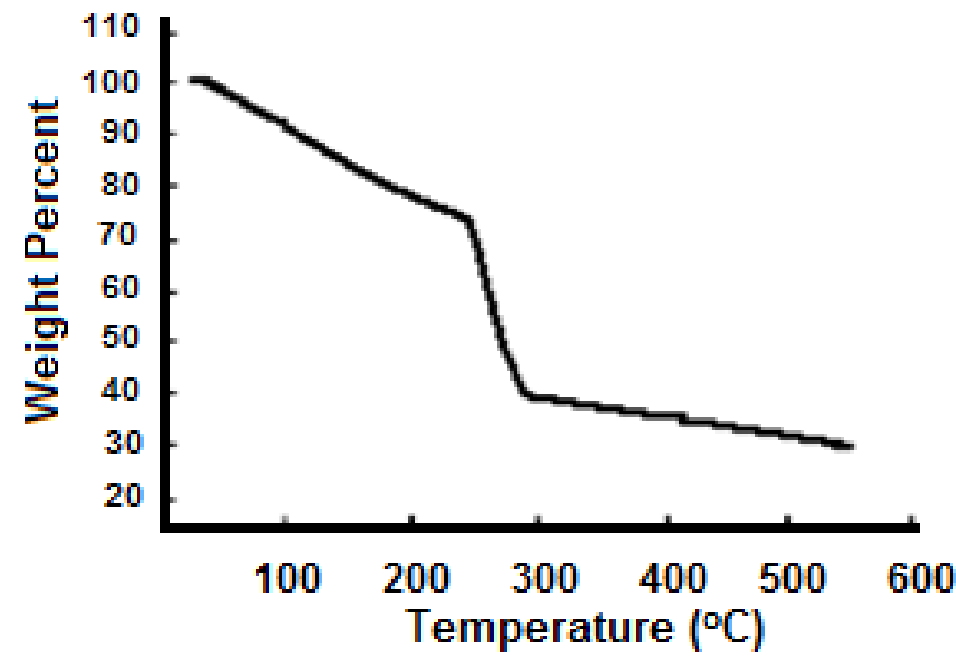

Fig.-4:Thermogravimetric Analysis (TGA) of Carboxymethyl Chitosan

\section{EXPERIMENT}

The water sample was collected from River Indus. The samples were collected according to standard procedure and analyzed without delay. Before collection of the sample all the samples bottles were soda washed rinsed with double distilled water and sterilized. All the samples bottle were make free from all the contaminations. The samples were analyzed by the calibrated equipments. The samples were collected in each month of 2011. Each and every sample was collected repeatedly in order to validate. The samples were collected in air tight sampling bottles and capped properly. The analyses were carried out without delay. The standard procedure was followed in sampling. 


\subsection{Optimization of Dose of Carboxymethyl Chitosan for Turbidity Removal}

In order to observe the optimum dose of Carboxymethyl Chitosan, the six samples were taken and their turbidity level were maintained at 10 FTU, 20 FTU, 40 FTU, 60 FTU, 80 FTU and 100 FTUas shown in Figure5. During study it was observed that at low dose of Carboxymethyl Chitosan, the low turbidity removal percentage was obtained. The study was started by adding $0.1 \mathrm{mg}$ of Carboxymethyl Chitosan in one liter of water samples. The samples turbidity was already set at 10 FTU, 20 FTU, 40 FTU, 60 FTU, 80 FTU and 100 FTU. After adding the Carboxymethyl Chitosan in each tube it was stirring well. The flocculant was water soluble. The samples were kept for settling at desk for 30 minute. The turbidity was noted by turbidity meter. The experiments reflected that low dose of Carboxymethyl Chitosan exhibit the low percentage of turbidity removal. The $0.1 \mathrm{mg} / \mathrm{L}$ Carboxymethyl Chitosan removed the turbidity averagely $82.67 \% \pm 1.81 \%$, or $82.67 \% \pm$ $2.19 \%$. As the dose of Carboxymethyl Chitosan increased at $0.2 \mathrm{mg} / \mathrm{L}$, the turbidity removal percentage were enhanced and stands at $84.9 \% \pm 2.53 \%$ or $84.9 \% \pm 2.98 \%$. By followed up experimental conditions, the doses of Carboxymethyl Chitosan were slowly increased as $0.3 \mathrm{mg}, 0.4 \mathrm{mg}, 0.5 \mathrm{mg}$ and $0.8 \mathrm{mg}$ per liter of water sample. The experimental conditions revealed that doses increment beyond optimum level causes destabilization of bottom layer of settled particles. It was concluded that optimum dose were $0.2 \mathrm{mg}$ per one liter of sample. There was small difference observed between the doses from $0.5 \mathrm{mg}-0.7 \mathrm{mg}$. However the mean turbidity removal percentages were as $83.52 \% \pm 3.01 \%$ Or $83.52 \% \pm 3.6 \%$ against $0.3 \mathrm{mg}, 81.67 \% \pm 3.24 \%$ or $81.67 \% \pm 3.97 \%$ for $0.4 \mathrm{mg}, 81.33 \% \pm 3.32 \%$ Or $81.33 \% \pm 4.08 \%$ for $0.5 \mathrm{mg}$ and $80.78 \% \pm 3.63 \%$ or $80.78 \% \pm 4.49 \%$ for $0.8 \mathrm{mg}$ per liter.

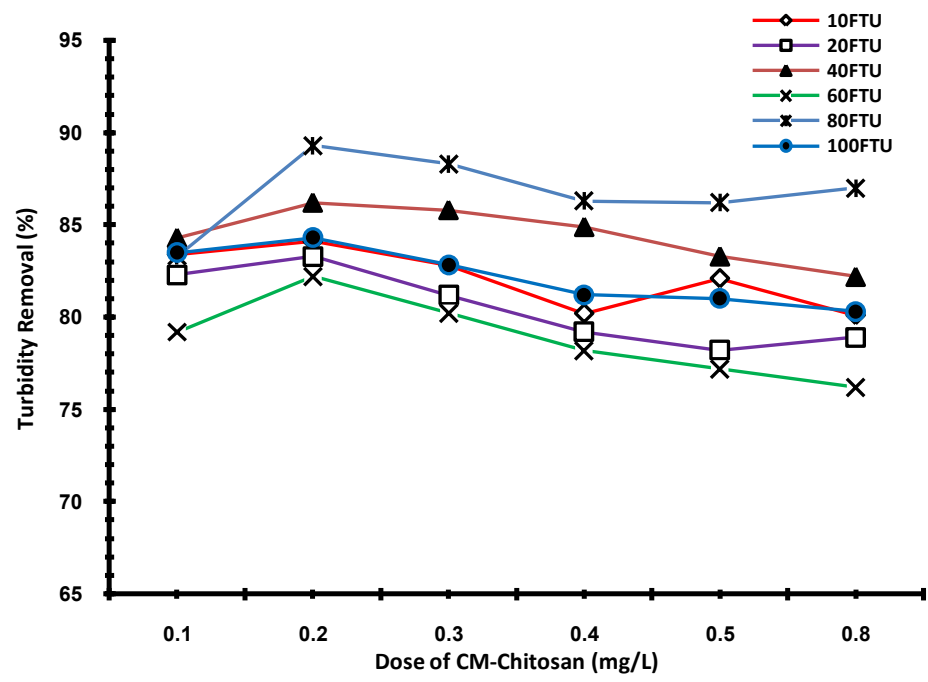

Fig.-5: Plot shows the Carboxymethyl Chitosan dosage (mg/L) for the Turbidity Removal (FTU)

\subsection{Optimization of pH of Carboxymethyl Chitosan}

The $\mathrm{pH}$ of suspension influences the flocculation process. The turbidity removal efficiency varies with the variation in $\mathrm{pH}$ of suspensions. To study optimum $\mathrm{pH}$ value the research were carried out by taken water samples maintained at the range of $\mathrm{pH} 4-\mathrm{pH} 10$. The $\mathrm{pH}$ was maintained by $1 \mathrm{M}$ Sodium Hydroxide solution and $1 \mathrm{M}$ Hydrochloric acid. The $\mathrm{pH}$ was monitored by using $\mathrm{pH}$ Meter (Thermo Orion Model $420 \mathrm{~A}^{+}$, USA) with combined glass electrode. The optimum dose of Carboxymethyl Chitosan was added to the samples.The samples were agitated well. After agitation it was settled for 30 minute. According to experimental results the maximum solids settling were done at neutral suspension. It was concluded that the maximum turbidity removed from the sample at $\mathrm{pH} 7$ and at that value the residual turbidity level became high and clear interface appeared as shown in Figure-6. It was also found that when $\mathrm{pH}$ increased above the optimum level than destabilization of suspension was occur and clear interface were not appeared. At the $\mathrm{pH} 4$ the mean turbidity removal percentage were $81.16 \%$, at $\mathrm{pH} 5$ it was stand at $82.43 \%$, at $\mathrm{pH} 6$ it was $85 \%$, and at $\mathrm{pH} 7$ it was $87.8 \%$. When the $\mathrm{pH}$ increases from its optimum level than the turbidity removal percentage were decreases and it was noted that at $\mathrm{pH} 8$ it was $85.46 \%$ and at $\mathrm{pH} 9$ it stands $84.36 \%$, and at $\mathrm{pH} 10$ it was $83.4 \%$. The given figure expressed the minimum, maximum and mean value of turbidity removal in FTU. The $\mathrm{pH} 4, \mathrm{pH} 5$, and $\mathrm{pH} 6$ the Minimum and Maximum turbidity removal percentage were as $79.4 \%-82.4 \%, 80.4 \%-83.56 \%$ and $82.4 \%-86.5 \%$ respectively. The below optimum $\mathrm{pH}$ it was $83.4 \%-88.3 \%, 82.2 \%-87.4 \%$ and $81.1 \%-86.4 \%$ against the $\mathrm{pH} 8$, $\mathrm{pH} 9$, and $\mathrm{pH} 10$ respectively. 


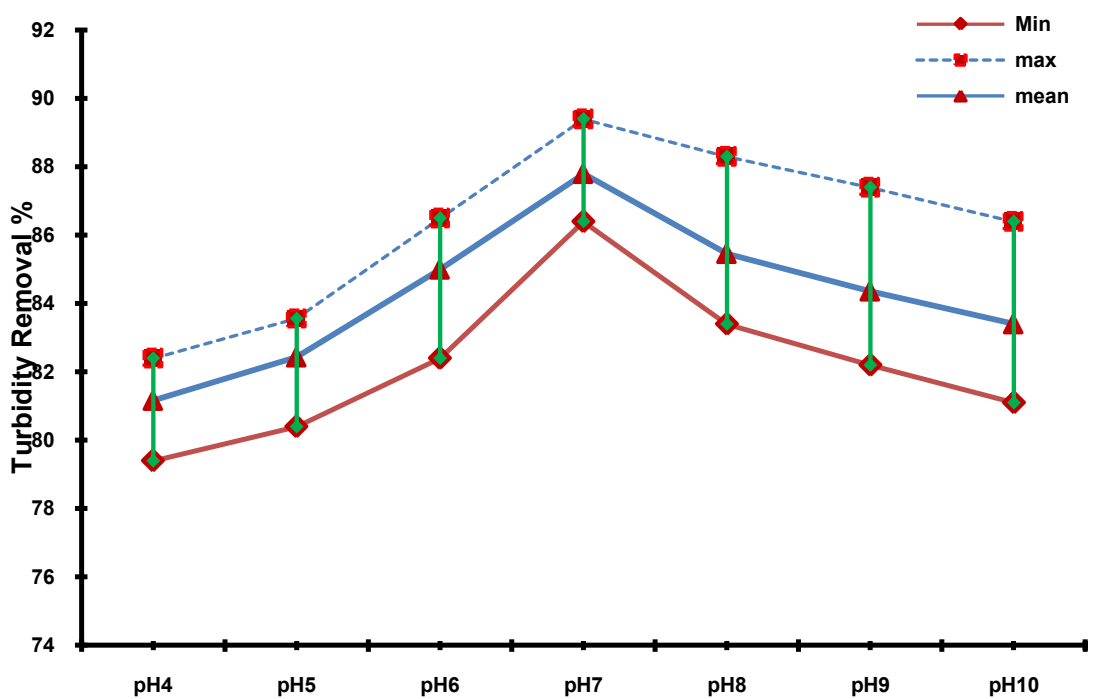

Fig.-6: The optimum $\mathrm{pH}$ at which maximum turbidity removed using Carboxymethyl Chitosan.

The vertical bars shows the standard deviation after six repetition

\section{RESULTS AND DISCUSSION}

Initial turbidity of sample refers the turbidity of sample before adding Carboxymethyl Chitosan. After adding the Carboxymethyl Chitosan at optimum condition and specific settling time the particle settling down in bottom and clear interface was obtained in top. The clear interface on top known as Supernatant, while at bottom side sediment or thick layer observed that contain high concentration of solid particles. That bottom layer known as Residual turbidity of sample. The residual turbidity is the difference between initial turbidity and supernatant clarity of sample. The residual turbidity and supernatant clarity were interrelated term. At higher supernatant clarity the maximum residual turbidity was observed. The separation efficiency shows the effectiveness of flocculant or in other words tells us how much upper layer is free from solid particles and how many solid particles settle down. Separation efficiency computed here in terms of residual turbidity of sample.

According to data obtained it was clear that initial turbidity were stands between 10.5 FTU to 19.1FTU as depicted in Figure-7.After adding Carboxymethyl Chitosan at optimum dose and optimum pHthe particle was settle down and after 30 minute the separation efficiency was stands between $81.2 \%-87.1 \%$. Without flocculant the separation efficiency was stands between $42.2 \%-48.32 \%$. The mean value of separation efficiency with CMChitosan was $85.15 \%$ and $45.49 \%$ without CM-Chitosan. The maximum and minimum turbidity was observed in the month of March and May.

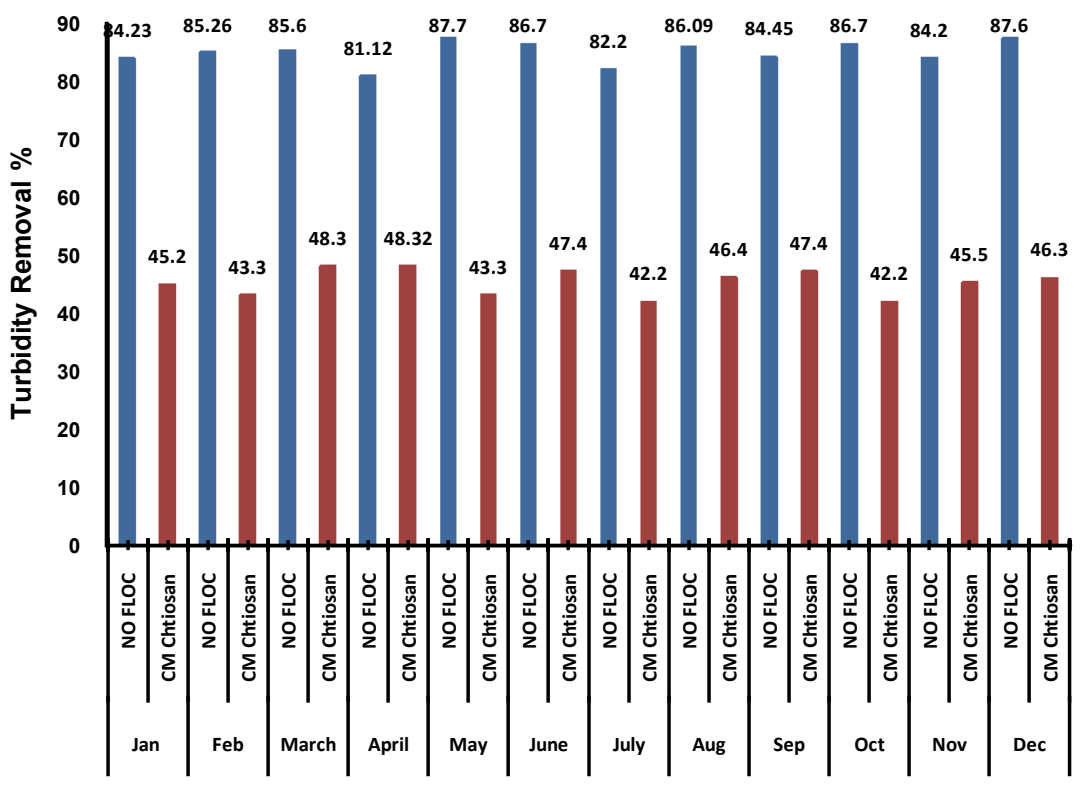

Fig.-7: The mean separation efficiencies of water samples collected from River Indus in 2011 using CM-Chitosan as flocculant 
VI.

CONCLUSION

\subsection{Total Suspended Solids and Turbidity Relationship}

It was observed after conducting the test that there is linear relationship between the total suspended solids and turbidity. The results are expressed graphically in Figure- 8 .

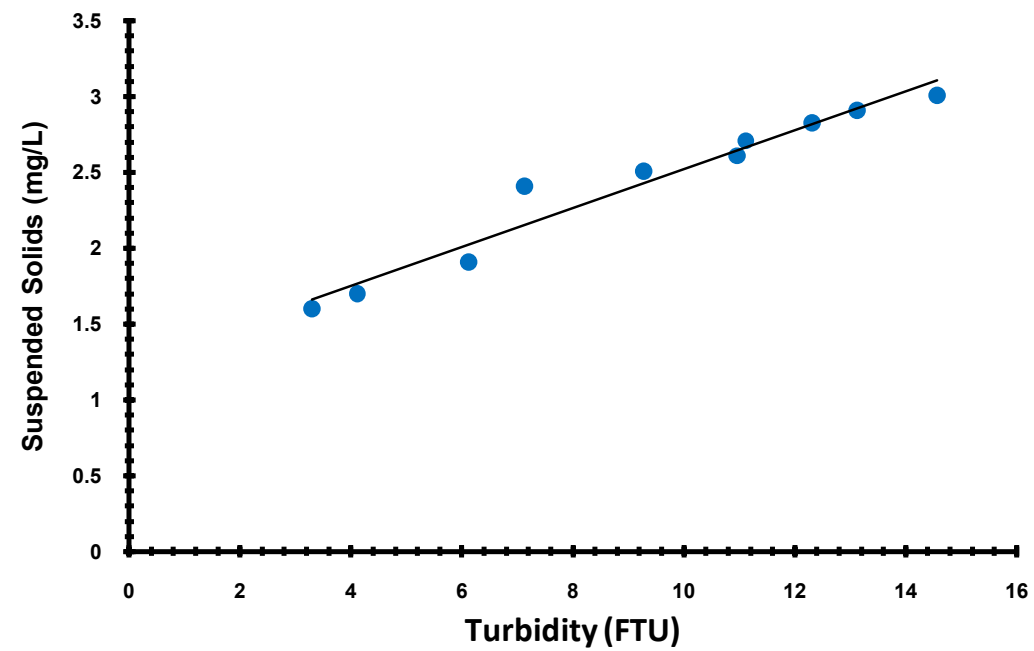

Fig.-8: Graph Plot shows the linear relationship between Total Suspended Solids (mg/L) and Turbidity (FTU)

\subsection{Relationship between initial Turbidity and Dosage}

Research shows that there is relationship between the flocculation dosage and turbidity removal however it is independent of initial turbidity of sample. The optimum dosage was found $3 \mathrm{mg} / 100 \mathrm{~mL}$. At higher dosage the particle destabilize and disperse in suspension resulting suspended particle concentration increase. The maximum sediment bed obtained at dose $3 \mathrm{mg} / 100 \mathrm{~mL}$. The turbidity removal efficiency affected by the container/vessel designing feature. The free settling promotes high settling rate. The high initial concentration of solid particles and low container/vessels volume causes hindered settling. The hindered settling takes comparatively long time to settle because the particles collides each other and walls of container.

\subsection{Settling Rate and Time Relationship}

When optimum condition of $\mathrm{pH}$ and flocculant dose was maintained in river water samples than tests were conducted to observe the settling rate verses time. It was observed that highest settling occur in staring 5 minute. The suspended particle quickly settles down in bottom and agglomerates and make floccus. The bridging mechanism would be high in starting 5 minute, here $64 \%$ settling occurs. In between 5 minute to 10 minute, the transition time starts here settling rate become slower and reaches to $19 \%$. The particles disperse in medium and slowly move down. After 15 minute rest of the particle in suspension settle down. A porous particle bed formed bottom in 30 minute. After this time porosity of bed decrease and bed consolidate its height decrease few centimeters after 60 minutes.

\section{ACKNOWLEDGEMENT}

The authors are thankful to the Faculty of Chemical Engineering Department, MUET, Jamshoro Pakistan, IARSCS and Dr M A Kazi Institute of Chemistry, University of Sindh, Jamshoro, Pakistan for providing research facilities at Analytical Chemistry Labs. The Morphology of Carboxymethyl Chitosan was observed by Scan Electron Microscope (SEM) in Scanning Electron Microscope Laboratory, Centre of Pure and Applied Geology University of Sindh Jamshoro.Fourier Transform Spectroscopy of Carboxymethyl Chitosan was conducted in M. A. Kazi Institute of Chemistry, University of Sindh, Jamshoro.The Thermal Gravimetric Analyses (TGA) of Carboxymethyl Chitosan was conducted in PCSIR Lab Karachi.

The authors are also thankful to Mr. Hussain Saleem, Assistant Professor \&Incharge SoftronixScience Simulation Lab(FF-21, UBIT Building), Department of Computer Science, University of Karachi, Pakistan for providing support for performing data analysis and software based simulation, and document processing of this Research paper. 


\section{REFERENCES}

[1] Abdul Karim Shah, Zeenat M. Ali, Abdul RehmanMemon, A. JabbarLaghari, Moina Akhtar Mughal, Syed Farman Ali Shah, Hussain Saleem, (2013), "Exploitation of Low Cost Coal Fly Ash Adsorbent with Coagulants for the Treatment of Industrial Complex Nature Dyes Wastewater", IJSER Vol. 4, Issue 9, pp.109-119.

[2] Khanafari, A., Marandi, R. E. Z. A., \&Sanatei, S., (2008), "Recovery of chitin and chitosan from shrimp waste by chemical and microbial methods", Iranian Journal of Environmental Health Science \& Engineering, Vol. 5, Issue No.1, pp.19-24.

[3] Liang Chen, Donghuichan and Chongliangwu, (2003), Journal of Polymer and Environment, Vol.11, No.3, pp.87-92.

[4] Moina Akhtar Mughal, Akhtar H. Mughal, Zeenat M. Ali, Mohammad Yar Khuhawar, Hussain Saleem, (2013), "Antimicrobial Viscometric Studies of Thermally Stable Metal based Schiff Base Polymer derived from 4, 4-Methylene Bis Furfuraldehyde", IJOART Vol. 2, Issue 8, pp.6-13.

[5] Moina Akhtar Mughal, Akhtar Mughal, Zeenat M. Ali, GhulamZuhraMemon, Mohammad Yar Khuhawar, Hussain Saleem, (2013), "New Antimicrobial Schiff base Polymers derived from 6, 6-Methylenebis (1-Napthaldehyde)", IJSER Vol. 4, Issue 9, pp.120-128.

[6] Mourya V. K., Inamdar N. N., Tiwari A., (2010), "Carboxymethyl Chitosan and its Applications", Review Article, Adv. Materials Letters, Vol.1, Issue 1, pp.11-33.

[7] Zeenat M. Ali, Moina Akhtar Mughal, A. JabbarLaghari, A. K. Ansari, Hussain Saleem, (2013), "Polymeric Cellulose Derivative: Carboxymethyl-Cellulose as useful Organic Flocculant against Industrial Waste Waters”, IJOART Vol. 2, Issue 8, pp.14-20.

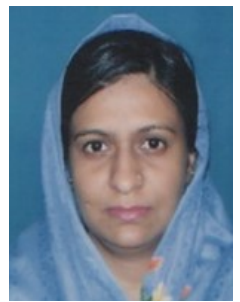

Zeenat Muhammed Ali is presently working as Assistant Professor in Chemical Engineering Department, Mehran University of Engineering \& Technology (MUET), Jamshoro, Sindh, Pakistan. She is Ph.D. Research Scholar. Her dissertation work is in final stages of submission. She has also obtained B.E. in Chemical Engineering in 1997 and M.E. in Environment Engineering in 2002 from MUET, Jamshoro. She has extensively worked in the area of Flocculation under Ph.D. studies and extracted natural flocculants from their indigenous sources and applied for water treatment for removal of turbidity, total dissolved solids and heavy metals. She has presented her work in various national and international conferences. Her work is published in various journals of repute.

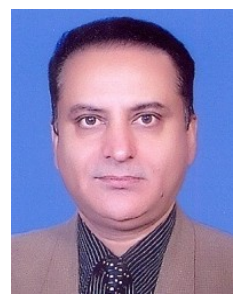

Abdul JabbarLaghari is presently working as Director (Incharge) of Institute of Advanced Research Studies in Chemical Sciences (IARSCS)/HRL, University of Sindh, Jamshoro, Pakistan and Ex-Officio of Dr. M. A. Kazi Institute of Chemistry, University of Sindh, Jamshoro, Pakistan. He has teaching experience of 17 plus years. He is Ph.D. and worked extensively on the development of new mixed stationary phases for gas chromatography and gas chromatographic determination of metal ions. $\mathrm{He}$ is author of various research articles.

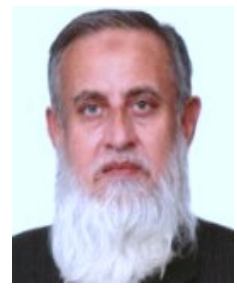

Abdul Khalique Ansari is Ph.D. and Professional Engineer having more than 35 years university teaching experience in the field of Chemical and Environmental Engineering. He is former Professor of Chemical and Environmental Engineering, MehranUnivrsity of Engg. \& Tech., Jamshoro, Sindh, Pakistan. Presently serving as Sr. Environmental Engineer, WSIP- I at M.M. Pakistan (Pvt) Ltd. He has been engaged for more than 14 years in different capacities at Administrative \& Management positions during his service. He has also served for 10 years as subject and field specialist, developed PC-1 for the establishment of Institute of Environmental Engineering in Mehran University, Jamshoro. He has worked for SIDA (Sindh Irrigation \& Drainage Authority) to bring reform to achieve goals of equitable and reliable water supply to all farmers through participatory irrigation. He have produced more than 50 research publications with good impact factor in national \& International journals of repute.

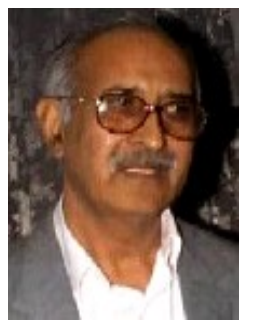

Muhammad Yar Khuhawar is Professor Emeritus, leading researcher and a versatile educator with distinguished academic carrier producing 25 Ph.D., 9 M.Phil. and 3 M.E. research scholars. He is honored with large number of National Awards, including Izaz-e-Kamal and Sitar-e-Imtiaz by President of Islamic Republic of Pakistan for achievements in scientific research. He is well known scholar having 35 years experience of teaching and research at higher education. Administrated number of fully funded research schemes and various academic tasks. National reputation for launching highly productive research workspace, in spite of meager research facilities available. He is actively committed to the field of research yielding over 283 publications in national and international journals. A large number of them are in the field of chromatography and electrophoresis for the analytical methods development for metals, non-metals and biological active compounds from wide variety of real samples; the synthesis of a number of schiff base polymers; new stationary phases for gas chromatography and sensitive liquid chromatography procedures for the determination of pesticide malathion. 